\title{
COMUNICAÇÃO
}

\section{CARACTERIZAÇÃO MOLECULAR DE CULTIVARES DE CANA-DE-AÇÚCAR UTILIZANDO MARCADORES ISSR}

\author{
Molecular characterization of the sugarcane cultivars obtained by issr markers \\ Clébia Maria Alves de Almeida1, Sue Ellen Nascimento de Lima², Gaus Silvestre de Andrade Lima ${ }^{3}$, \\ Júlio Zoé de Brito ${ }^{4}$, Virgínia Maria Tenório Sabino Donato ${ }^{5}$, Márcia Vanusa da Silva ${ }^{6}$
}

\begin{abstract}
RESUMO
A diversidade genética de catorze cultivares de cana-de-açúcar (Saccharum oficinarum) foi acessada por meio de marcadores moleculares ISSR. Objetivou-se caracterizar molecularmente as cultivares estudadas. Foram utilizados trinta e sete primers de ISSR, dos quais, oito foram eficientes na amplificação do DNA das amostras analisadas, sendo sete primers suficientes para distinguir todas as cultivares de cana-de-açúcar envolvidas nas análises. A faixa de amplicons variou de 300 a 2000 pb. As cultivares RB 92579 e RB 863129 apresentaram maiores coeficientes de similaridade (77\%) enquanto as cultivares RB 961 e RB 931611 formaram o grupo com menor similaridade (22\%). Os resultados indicam que os marcadores ISSR foram úteis na análise da diversidade genética e geração de padrões genéticos (fingerprint), em germoplasma de cana-de-açúcar. Marcadores ISSR cultivar-específico foram obtidos com o primer UBC 817 para as 14 cultivares testadas. Num próximo trabalho, mais primers ISSR serão utilizados para buscar mais polimorfismos dessas e de outras cultivares de cana-de-açúcar.
\end{abstract}

Termos para indexação: Saccharum oficinarum, marcadores moleculares ISSR, diversidade genética.

\section{ABSTRACT}

Genetic diversity of fourteen sugarcane cultivars was accessed by ISSR molecular markers. With the aim to characterizing and validating the efficiency of these markers in the fingerprint of studied cultivars, thirty seven ISSR primers were used, from which, eight were efficient for the DNA amplification. Seven primers were efficient to discriminate the fourteen studied sugarcane cultivars. The amplicons varied from 300 to 2000 bp. The cultivars RB 92579 and RB 863129 presented higher similarity coefficient (77\%) while the cultivars RB 961 and RB 93611 formed the group with lower similarity (22\%). The results suggested that ISSR markers were useful in the analysis of the genetic diversity and in the fingerprint in sugarcane germosplasm. In the next step more ISSR primers will be used in order to obtain more polymorphism from these varieties and to analyze more sugarcane cultivars.

Index terms: Saccharum oficinarum, molecular markers, genetic diversity.

\section{(Recebido em 5 de março de 2007 e aprovado em 25 de abril de 2008)}

A cana-de-açúcar (Saccharum officinarum) é uma cultura de grande importância econômica para alguns países da América, especialmente para o Brasil. O agronegócio da cana-de-açúcar, que reúne $6 \%$ dos empregos agroindustriais brasileiros, é responsável por 35\% do PIB do estado de São Paulo, maior produtor do país, e $10 \%$ do PIB de Pernambuco, segundo maior produtor do Nordeste
(SINDAÇÚCAR, 2005). Assim, a atividade canavieira do Brasil é responsável por cerca de um milhão de empregos diretos, o que destaca o seu potencial socioeconômico.

A busca constante de novas cultivares através do melhoramento genético tem possibilitado a seleção de genótipos mais promissores e adaptados às diversas condições edafoclimáticas do país (SIMÕES NETO et al.,

${ }^{1}$ Bióloga, Doutoranda em Ciências Biológicas - Programa de Pós-Graduação em Ciências Biológicas - Centro de Ciências Biológicas/PPGCB/CCB Universidade Federal de Pernambuco/UFPE - Av. Prof. Moraes Rego, 1235 - Cidade Universitária, Recife, PE - 50670-901 - clebia.almeida@gmail.com ${ }^{2}$ Bióloga - Departamento Biotecnologia - Laboratório de Biologia do Solo - Instituto Agronômico de Pernambuco/IPA - Avenida General San Martin, 1371 Bonji - 50761-000 - Recife, PE - suy.ellen@bol.com.br.

${ }^{3}$ Engenheiro Agrônomo, Doutor em Agronomia, Professor Adjunto II - Departamento de Fitossanidade - Universidade Federal de Alagoas - Centro de Ciências Agrárias, Br 104, Km 85, Norte - 57100-000 - Rio Largo, Al - gausandrade@yahoo.com.br.

${ }^{4}$ Engenheiro Agrônomo, Doutor em Botânica, Pesquisador - Diretoria de Pesquisa - Laboratório de Cultura de Tecidos - Instituto Agronômico de Pernambuco/IPA - Avenida General San Martin, 1371 - Bonji - 50.761-000 - Recife, PE - juliozoe@gmail.com

${ }^{5}$ Engenheira Agrônoma, Doutora em Botânica, Professora Adjunta - Departamento de Biologia - Universidade Federal Rural de Pernambuco - Rua Dom Manoel de Medeiros, s/n - Dois Irmãos - 52171-900 - Recife, PE - vmtsdonato@uol.com.br

${ }^{6}$ Engenheira Agrônoma, Doutora em Biologia Molecular, Professora Adjunta - Centro de Ciências Biológicas - Departamento de Bioquímica/CCB/ Departamento de Bioquímica - Universidade Federal de Pernambuco - Av.Prof. Moraes do Rego s/n, Cidade Universitária, Recife, PE - 50650-420 marcia.vanusa@ufpe.br 
1999). Com o desenvolvimento de novas cultivares tem crescido, nas últimas décadas, o interesse pela caracterização de cultivares em todo o mundo, devido à necessidade de proteção de cultivares comerciais em um mercado econômico cada vez mais competitivo (MILACH, 1999). As diferenças entre cultivares podem ser determinadas, utilizando-se descritores bioquímicos, morfológicos e moleculares. Os dois primeiros apresentam limitações em relação à influência do meio ambiente e ao número limitado de descritores fenotípicos. Os descritores de DNA apresentam a vantagem de representar todo o genótipo, mantendo consistência nos resultados, evitando o problema da expressão do fenótipo (WUNSCH \& HORMAZA, 2002). A possibilidade de acessar a variabilidade genética diretamente em nível de DNA, vem fazendo com que, cada vez mais, sejam disponibilizadas técnicas precisas que possam vir auxiliar o processo de proteção intelectual de materiais genéticos (PADILHA et al., 2002).

Diversos métodos de análise molecular, ao nível de DNA têm sido utilizados em estudos de variabilidade em plantas, no intuito de identificar e determinar relações ao nível de espécies e cultivares. Entre esses, marcadores do tipo RAPD tem sido empregado com sucesso em culturas de importância econômica, tais como açaizeiro (OLIVEIRA et al., 2007) e seringueira (BICALHO et al., 2008). O método de ISSR (inter simple sequence repeat) tem sido amplamente utilizado nesses estudos por ser uma técnica simples, eficiente, possuir alta reprodutibilidade e gerar altos índices de polimorfismo (REDDY et al., 2002). Vários estudos têm apresentado alto conteúdo de informação genética revelado por estes marcadores, que parecem ser especialmente apropriados para estudos filogenéticos, de avaliação da diversidade genética e identificação de cultivares (RAKOCZY-TROJANOWSKA \& BOLOBOK, 2004). Objetivou-se, neste trabalho acessar a viabilidade da técnica de PCR-ISSR, no estudo do genoma de cultivares de cana-de-açúcar e detectar variações, ao nível de DNA, das catorze cultivares de cana estudadas.

Catorze cultivares de cana-de-açúcar, na forma de cana semente, fornecidas pelo Programa de Melhoramento Genético de Cana-de-Açúcar de Alagoas (PMGCA) (Tabela 1) foram utilizadas para a caracterização molecular. Essas cultivares são empregadas em programas de melhoramento desenvolvidos pela Rede Interuniversitária de Desenvolvimento do Setor Sucroalcooleiro - RIDESA.

O DNA genômico total das cultivares estudadas, foi extraído segundo a metodologia descrita por Ferreira \& Grattapaglia (1998). A quantificação e qualidade do DNA foram avaliadas em eletroforese em gel de agarose $1 \%(\mathrm{p} / \mathrm{v})$, em tampão TBE 1X (Tris borato 0,09M EDTA 0,002M) em 80 Volts, durante 30 minutos. A quantificação da concentração de DNA existente em cada amostra foi realizada por análise comparativa em géis de agarose corados com SyBr Gold 1X (Molecular Probe). O tamanho e intensidade dos fragmentos produzidos pelas amostras de DNA extraídas das plantas foram comparados com os fragmentos produzidos por amostras de concentrações conhecidas. Essas amostras foram preparadas a partir de diferentes volumes de DNA Lambda (Gibco BRL, Life Technologies). Foram produzidas amostras de 10, 20 e $50 \mathrm{ng}$ de DNA/mL.

Tabela 1 - Cultivares de cana-de-açúcar utilizadas nas análises moleculares com suas respectivas identificações, correspondentes aos grupos formados no dendrograma (Figura 1).

\begin{tabular}{cc}
\hline Cultivares & Representação no dendrograma \\
\hline RB 943365 & A \\
RB 9364 & B \\
RB 931011 & C \\
RB 92579 & $\mathrm{D}$ \\
RB 863129 & $\mathrm{E}$ \\
RB 94503 & $\mathrm{F}$ \\
RB 931530 & $\mathrm{G}$ \\
RB 931003 & $\mathrm{H}$ \\
RB 961552 & $\mathrm{I}$ \\
RB 9622 & $\mathrm{J}$ \\
RB 961 & $\mathrm{~L}$ \\
RB 951541 & $\mathrm{M}$ \\
RB 9629 & $\mathrm{~N}$ \\
RB 931611 & $\mathrm{O}$ \\
\hline
\end{tabular}

Ciênc. agrotec., Lavras, v. 33, Edição Especial, p. 1771 -1776, 2009 
Os ensaios de ISSR foram baseados no método descrito por Zietkiewicz et al. (1994), utilizando-se primers ancorados, tendo as reações sido otimizadas para a obtenção de produtos de amplificação de melhor qualidade. Foram empregados 37 primers ISSR, publicados pela University of British Columbia (UBC), Vancouver, Canadá, para a geração de polimorfismo. As amplificações do DNA foram realizadas em termociclador MJ Research, Inc. PTC 100 (Watetown, USA), com volume final de $25 \mathrm{iL}$ para cada reação, contendo $10 \mathrm{mM}$ de Tris- $\mathrm{HCl}(\mathrm{pH} \mathrm{8,0),} 2 \mathrm{mM}$ de $\mathrm{MgCl}_{2}, 100 \mu \mathrm{M}$ de cada desoxirribonucleosídeo trifosfato (DNTPs), 0,2 $\mu \mathrm{M}$ do primer, uma unidade da enzima Taq DNA polimerase e $15 \mathrm{ng}$ de DNA. Nas reações de PCR, as amostras foram submetidas inicialmente a $94^{\circ} \mathrm{C}$ por 5 minutos, e, a seguir, a 30-35 ciclos de amplificação. Cada ciclo submeteu as amostras a $94^{\circ} \mathrm{C}$ por 30 segundos, com temperatura de anelamento variando de $50-55^{\circ} \mathrm{C}$ (dependendo do primer utilizado), por 45 segundos e por fim $72^{\circ} \mathrm{C}$, por 2 minutos. Após os ciclos, as amostras foram mantidas a $72^{\circ} \mathrm{C}$ por 5 minutos, para extensão final. Os produtos da reação foram separados em eletroforese em gel de agarose 2\% em Tampão TBE 1X, e corados com SyBr Gold 1X (Molecular Probe) e fotografados sob luz UV, em um fotodocumentador digital, Vilber Lourmat .

O padrão dos produtos de ISSR amplificados se comportam como marcadores dominantes e foram tabulados com presença (1) e ausência (0) para cada cultivar de cana estudada. $\mathrm{O}$ peso molecular de cada fragmento foi estimado com base no Marcador de DNA $1 \mathrm{~kb}$ (1kb Ladder Plus, Invitrogen). Os marcadores obtidos foram analisados pelo Programa Genes versão 2005.6.1 (CRUZ, 2001), em que foi gerada uma matriz de similaridade genética utilizando o coeficiente de Jaccard e construído um dendrograma pelo método de agrupamento UPGMA.

Neste trabalho, foram utilizadas amostras de DNA de catorze cultivares de cana-de-açúcar (Tabela 1) e 37 primers ISSR com o objetivo de selecionar os mais informativos. Do total de primers testados, oito forneceram produtos nítidos de amplificação e boa reprodutibilidade, sendo dois deles 5' ancorados e os demais 3' ancorados (Tabela 2). Os primers utilizados nesse estudo amplificaram o DNA de cana-de-açúcar com diferentes eficiências. Vários estudos relatam que os primers ISSR 5' ancorados geram produtos mais informativos (MATTHEWS et al., 1999). Entretanto, nesse estudo, primers 3' ancorados foram mais eficientes na amplificação de fragmentos específicos.

A correta identificação genética de germoplasmas é uma questão de crescente importância para a produção vegetal (MILACH, 1999). O desenvolvimento de novas cultivares, como também a caracterização das tradicionais, impulsiona o desenvolvimento de novas técnicas que permitam uma identificação precisa dos materiais. Em vista da extensa coleção de recursos genéticos de cana e a importância desses recursos (germoplasma) para o sucesso de futuros programas de melhoramento, é essencial determinar a variabilidade genética em cultivares de canade-açúcar. Por meio do uso de perfis de DNA, empregando vários marcadores moleculares tais como, RFLP, RAPD e microssatélites, a identidade genética de cada acesso ou cultivar pode ser determinada (BROWN \& KRESOVICH, 1996). Análises com marcadores RFLP têm revelado que as cultivares modernas de cana-de-açúcar são altamente heterozigóticas, apresentando vários alelos distintos por loco (GRIVET \& ARRUDA, 2001). Contudo, marcadores baseados em PCR são mais adequados para análises em larga escala (JOSHI et al., 2000). Marcadores moleculares do tipo ISSR (seqüências internas simples repetidas), os quais foram primeiro descritos por Zietkiewicz et al. (1994), é simples e não requer o conhecimento prévio da seqüência do genoma que está sendo testado. Esse método usa primers únicos de 15-20 nucleotídeos 3' ou 5' ancorados. Marcadores ISSR têm sido amplamente empregados para detectar polimorfismos intraespecíficos em plantas, como citrus, amedoim e arroz (PHARMAWATI et al., 2004).

Blair et al. (1999) obtiveram, em arroz, maior porcentagem de fragmentos polimórficos com marcadores ISSR quando comparados a marcadores AFLP. O alto nível de polimorfismo dos marcadores ISSR detectado nas cultivares de cana facilitou o desenvolvimento de um fingerprinting de DNA. A identificação de cultivares de cana-de-açúcar tem sido feita, principalmente, por meio de características morfológicas. Uma certificação genética baseada no padrão de bandeamento dos marcadores ISSR, que podem ser usados para identificar cultivares de cana, foram agora gerados. Esse padrão genético pode ser desenvolvido usando apenas um primer, UBC $817{ }_{650-2000}$ Um único primer de ISSR também foi usado por Arnau et al. (2003) na diferenciação de 30 cultivares de morango, demonstrando o alto poder de discriminação dessa técnica. A reprodutibilidade das amplificações foi acessada utilizando os primers UBC 812, 817 e 858 com diferentes amostras de DNA isoladas independentemente de cada cultivar e amplificadas em reações independentes. Sob condições de otimização, os perfis de amplificação foram consistentes entre todos os experimentos de PCR (dados não apresentados). 
Um total de 56 amplicons foram obtidos, com média de 7 amplicons por primer, sendo que 53 desses amplicons foram polimórficos (95\%) (Tabela 2). Segundo Colombo et al. (1998), 7 a 30 primers gerando de 50 a 200 amplicons polimórficos, são suficientes para estimar relações genéticas dentro e entre espécies. Kantety et al. (1995), utilizando dez primers obtiveram uma taxa de polimorfismo de $95 \%$ com 54 amplicons polimórficos em populações de Zea mays.

A análise geral do agrupamento, gerado pelo método UPGMA, resultou na formação de seis grupos (Figura 1), considerando o corte de $40 \%$. O grupo 2 concentrou o maior números de cultivares (A,B, N e H), apresentando, juntamente com o grupo 1 (cultivares L e O) um nível de similaridade de $60 \%$.

A similaridade genética entre as cultivares calculada com base em dados moleculares apresentou resultados consistentes, em decorrência de não haver interferência do ambiente, o que é comum em dados fenotípicos.

Esses resultados sugerem que genótipos distintos têm sido utilizados nos programas de melhoramento desenvolvidos pela RIDESA e que os marcadores ISSR são promissores no acesso da diversidade genética e identificação de fingerprinting de DNA, tendo potencial para identificar marcadores cultivar-específicos em cana-de-açúcar.

\section{AGRADECIMENTOS}

Ao Professor Geraldo Veríssimo, do Programa de Melhoramento Genético de Cana-de-açúcar da Universidade Federal de Alagoas, por disponibilizar o material vegetal e ao Conselho Nacional de Desenvolvimento Científico e Tecnológico/CNPq, pela concessão de recurso financeiro.

Tabela 2 - Lista dos primers selecionados para a amplificação do DNA das cultivares de cana-de-açúcar, com suas respectivas seqüências de bases, números de amplicons e polimorfismo detectado.

\begin{tabular}{ccccc}
\hline $\begin{array}{c}\text { Primers } \\
\text { UBC }\end{array}$ & Seqüência $\left(5^{\prime} \rightarrow 3^{\prime}\right)$ & $\begin{array}{c}\text { Numero de } \\
\text { amplicons totais }\end{array}$ & $\begin{array}{c}\text { No. de amplicons } \\
\text { polimorficos }\end{array}$ & $\begin{array}{c}\text { Polimorfismos } \\
(\%)\end{array}$ \\
\hline 812 & GAG AGA GAG AGA GAG AA & 6 & 6 & 100 \\
817 & CAC ACA CAC ACA CAC AA & 6 & 6 & 100 \\
848 & CAC ACA CAC ACA CAC ARG & 10 & 10 & 100 \\
858 & TGT GTG TGT GTG TGT GRT & 7 & 6 & 86 \\
864 & ATG ATG ATG ATG ATG ATG & 8 & 7 & 87,5 \\
878 & GGA TGG ATG GAT GGA & 4 & 4 & 800 \\
888 & BDB CAC ACA CAC ACA CA & 9 & 6 & 100 \\
890 & VHV GTG TGT GTG TGT GT & 6 & Total: 53 & $95 \%$ \\
\hline
\end{tabular}

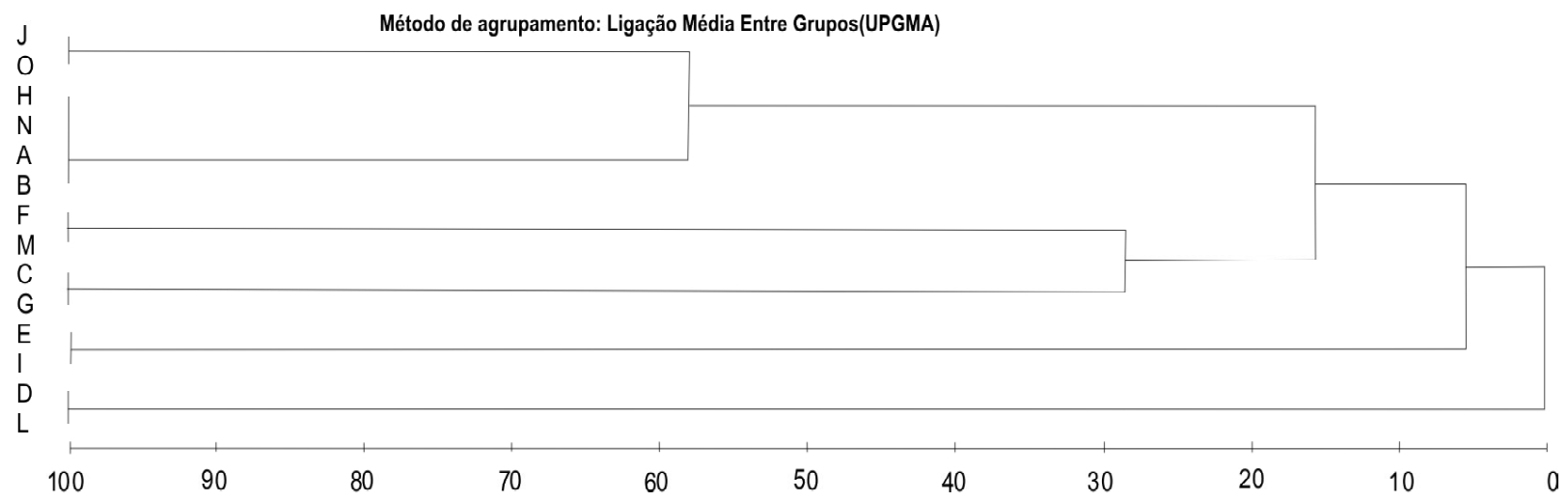

Figura 1 - Similaridade genética de cultivares de cana-de-açúcar baseada em marcadores ISSR. 


\section{REFERÊNCIAS BIBLIOGRÁFICAS}

ARNAU, G.; LALLEMAND, J.; BOURGOIN, M. Fast and reliable strawberry cultivar identification using inter simple sequence repeat (ISSR) amplification. Euphytica, Dordrecht, v. 129, n. 1, p. 69-79, 2003.

BICALHO, K. C. OLIVEIRA, L. E. M. de; SANTOS, J. B. dos; MESQUITA, A. C.; MENDONÇA, E. G. Similaridade genética entre clones de seringueira (Hevea brasiliensis), por meio de marcadores RAPD. Ciência e Agrotecnologia, Lavras, v.32, n.5, p. 1510-1515, set./out., 2008.

BLAIR, M. W.; PANAUD, O.; MCCOUCH, S. R. Intersimple sequence repeat (ISSR) amplification for analysis of microsatellite motif frequency and fingerprinting in rice (Oryza sativa L.). Theoretical and Applied Genetics, Stuttgart, v. 98, n. 5, p. 780-792, 1999.

\section{BROWN, S. M.; KRESOVICH, S. Genome mapping in plants. New York: Landes, 1996.}

COLOMBO, C. et al. Genetic diversity characterization of cassava cultivars (Manihot esculenta Crantz) with RAPD markers. Genetics and Molecular Biology, Ribeirão Preto, v. 21, n. 1, p. 105-113, 1998.

CRUZ, C. D. Programa Genes versão Windows: aplicativo computacional em genética e estatística. Viçosa, MG: UFV, 2001. 648 p.

FERREIRA, M. E.; GRATTAPAGLIA, D. Introdução ao uso de marcadores em análise genética. 3. ed. Brasília, DF: Embrapa-Cenargen, 1998. 220 p.

GRIVET, L.; ARRUDA, P. Sugarcane genomics: depicting the complex genome of an important tropical crop.

Current Opinion in Plant Biology, Amsterdam, n. 5, p. 122-127, 2001.

JOSHI, S. P. et al. Genetic diversity and phylogenetic relationship as revealed by inter simple sequence repeat (ISSR) polymorphism in the genus Oryza. Theoretical and Applied Genetics, Stuttgart, v. 100, n. 8, p. 1311-1320, 2000.

KANTETY, R. V. et al. Assessment of genetic diversity in dent and popcorn (Zea mays L.) inbred lines using intersimple sequence repeat (ISSR) amplification. Molecular Breeding, n. 1, p. 365-373, 1995.
MATTHEWS, D. et al. 5'-anchored simple-sequence repeat primers are useful for analysing potato somatic hybrids. Plant Cell Reports, Windsor, v. 19, n. 2, p. 210212, 1999.

MILACH, S. C. K. Disponibilidade de técnicas moleculares para la caracterização varietal. In: PAGLIANO, D. (Coord.). Calidad genética y sanitaria: um instrumento para la competitividad de la cadena agroindustrial. Montevideo: IICA-PROCISUR, 1999. p. $39-46$.

OLIVEIRA, M. do S. P. de; AMORIM, E. P.; SANTOS, J. B. dos; FERREIRA, D. F. Diversidade genética entre acessos de açaizeiro baseada em marcadores RAPD. Ciência e Agrotecnologia, Lavras, v. 31, n.6, p.1645-1653, nov./dez., 2007.

PADILHA, L. et al. Microssatélites fluorescentes na diferenciação de linhagens de milho. In: CONGRESSO NACIONAL DE MILHO E SORGO, 2002, Florianópolis, SC. Anais... Florianópolis, 2002. Disponível em: ¿www.abms.org.br/resumo37.doc?. Acesso em: 10 out. 2007 .

PHARMAWATI, M.; YAN, G.; MCFARLANE, I. J. Application of RAPD and ISSR markers to analyse molecular relationships in Grevillea (Proteaceae). Australian Systematic Botany, Collingwood, n. 17, p. 49-61, 2004.

RAKOCZY-TROJANOWSKA, M.; BOLIBOK, $\mathrm{H}$. Characteristics and a comparison of three classes of microsatellite-based markers and their application in plants. Celular \& Molecular Biology Letters, Wroclaw, v. 9, p. 221-238, 2004.

REDDY, M. P.; SARLA, N.; SIDDIQ, E. A. Inter simple sequence repeat (ISSR) polymorphism and its application in plant breeding. Euphytica, Dordrecht, v. 128, p. 9-17, 2002.

SIMÕES NETO, D. E.; MOREIRA, C. N.; LIMA, R. O. R.; MELO, L. J. O. T. Desempenho de genótipos de cana-de-açúcar (Saccharum spp) em diferentes ambientes do Estado de Pernambuco. In: CONGRESSO NACIONAL DA STAB, 7., 1999, Londrina, PR. Anais... Londrina, 1999. p. 29-33.

SINDAÇÚCAR. Associação dos produtores de açúcar e de álcool de Pernambuco. Recife, 2005. 
WUNSCH, A.; HORMAZA, J. I. Cultivar identification end genetic fingerprinting of temperate fruit tree species using DNA markers. Euphytica, Dordrecht, v. 125, p. 5967, 2002.
ZIETKIEWICZ, E.; RAFALSKI, A.; LABUDA, D.

Genome fingerprinting by simple sequence repeat (SSR)anchored polymorphism chain reaction amplification. Genomics, Amsterdam, v. 20, p. 176-183, 1994. 